\title{
El alma romántica y el pensamiento mágico: Novalis
}

\section{The romantic soul and magical thinking: Novalis}

\author{
TERESA AIZPÚN BOBADILLA \\ Universidad Rey Juan Carlos, Madrid
}

Recibido: 24/01/2019 Aceptado: 07/03/2019

\begin{abstract}
RESUMEN
Novalis es un representante paradigmático y a la vez único de la Ilustración alemana. Defiende un modelo de conocimiento que partiendo del sujeto nos lleva a la reunificación con el mundo, basado en un razonamiento fundamentado en la ciencia del momento. Ese ejercicio, en el que el hombre se transforma y supera infinitamente, exige el mismo proceso para la naturaleza en y desde el hombre, es una transformación dialógica de ambos. Este proceso es una Gaia ciencia.

PALABRAS CLAVE

NOVALIS, ILUSTRACIÓN ALEMANA, PENSAMIENTO CREADOR, 'ROMANTIZACIÓN'/ROMANTISIEREN
\end{abstract}

\begin{abstract}
Novalis is a paradigmatic and at the same time unique, very representative of the German Enlightenment. It actually defends a model of knowledge that starting from the subject leads us to the reunification with the world, based on a reasoning, and also based on the science of the moment. This exercise, in which man transforms and infinitely surpasses, demands the same process for nature in man, is a dialogical transformation of both. This process is a Gaia science.

KEYS WORDS

NOVALIS, GERMAN ENLIGHTENMENT, CREATIVE KNOWLEDGE, ROMANTISIEREN
\end{abstract}

(C) Contrastes. Revista Internacional de Filosofía, vol. XXIV-N² (2019), pp. 61-79. ISSN: 1136-4076 Departamento de Filosofía, Universidad de Málaga, Facultad de Filosofía y Letras Campus de Teatinos, E-29071 Málaga (España) 
Dios (nos) quiere dioses

Estamos encargados de una misión: la de formar la tierra

(Novalis) ${ }^{1}$

Todo no es más que ritmo; el destino del hombre es un solo ritmo celeste como toda obra de arte es un ritmo único

(Hölderlin) $)^{2}$

PoDRÍAMOS DECIR QUE tanto la Ilustración como el Romanticismo son dos formas diferentes de evolución del movimiento renacentista de renovación: la una positivista y profundamente anti-religiosa (propio del espíritu revolucionario francés), y la otra filosófico-poética, no por ello menos científica, y profundamente espiritual (propio de la contra revolución propugnada por los alemanes ${ }^{3}$ ). Para los alemanes el Romanticismo fue su propia forma de Ilustración. Ambas buscan encontrar lo más verdadero en el hombre y su relación real con el mundo, volviendo al origen, corrigiendo excesos; para la Ilustración francesa esto significaba eliminar todos los falsos saberes, delimitando con claridad el campo de lo cognoscible y, por tanto, enfatizando la separación y expulsión del campo de lo racional de todo lo considerado como «no-científico». Esto tenía que conducir necesariamente al hombre a dominar el mundo, objeto de la ciencia. Para el Romanticismo, por el contrario, esta búsqueda del verdadero conocimiento, que también debía conducirnos a un dominio de lo real, significaba alcanzar la plenitud gracias a la capacidad creadora, retornando a la unidad originaria con el mundo, eliminando todos los falsos límites, aceptando lo que hoy denominaríamos, en términos de la psicología actual, 'la sombra'. Podríamos decir que la primera «purifica» limitando, la segunda, reinterpretando y expandiendo. En este sentido, la revolución romántica es fundamentalmente espiritual, porque se estructura en base a la idea de reconciliación, Versöhnung. El Idealismo alemán busca la unidad de todo lo real, es una Vereinigungsphilosophie y, por esta razón, su racionalismo no sólo no es antirreligioso, sino que, a menudo, la misma narración religiosa es la que se transforma en científica. ${ }^{4}$

1 Novalis, Gérmenes o Fragmentos. Sevilla: Renacimiento, 2006, pp. 52 y 56.

2 F. Hölderlin, Poemas de la locura. Madrid: Hiperión, 2006, p. 39.

3 «La noticia del terror causó en la filosofía alemana una profunda decepción» (D. Inerarity, Hegel y el romanticismo. Madrid: Técnos, 1993, p. 171). «El eco de la Revolución francesa en Alemania no hay que buscarlo tanto en la literatura política cuanto en la predicación teológica» (ib. p. 168).

4 Cfr. L. Margantin, Système minéralogique et cosmologie chez Novalis ou les plis de la terre. Paris: Ouverture philosophique, L'Harmattan, 1998, p. 71. 
Estas dos visiones se escenificaron, sin ir más lejos, en la lucha entre las dos teorías geológicas preponderantes en la época en que Novalis decidió dedicarse a las ciencias. ${ }^{5}$ En el s. XVIII, el Vulcanismo o Plutonismo y el Neptunismo representaban dos visiones opuestas de la génesis de la tierra. El Neptunismo, preponderante en Alemania y defendido con fuerza por los profesores de la Bergakademie, en la que estudió Novalis, defendía que el origen de la estructura del suelo está en el agua. Aceptaban así la narración bíblica frente a quienes defendían que el fuego era el elemento originario. En Alemania, el fuego tenía incluso concomitancias políticas negativas, pues se consideraba un elemento revolucionario. ${ }^{6}$ En Novalis, casi podríamos ver una unión de ambas en el fluido originario que constituye lo real y material, die Urflüssigkeit.

Esa unidad, a la que aspira el Romanticismo, tiene su origen en el interior del ser humano, frente al Empirismo ilustrado, para el que todo comienza y termina en el objeto y, por tanto, en el exterior. Esta es otra de las grandes diferencias entre ambas visiones. El yo juega en la Ilustración alemana un papel preponderante y hace posible esa inclinación hacia la faceta creativa y activa del ser humano, tan característica del Romanticismo y tan fascinante en el caso de Novalis. En la Ilustración francesa el mundo estaba para ser dominado, pero finalmente dominaba al hombre, pues limitaba su actuar y su pensar, el sujeto estaba realmente sometido a él. En el Romanticismo, el mundo y su unidad digamos el mundo del futuro-, sin ser algo ajeno a lo real, es una conquista, una creación, es una posibilidad de la capacidad creadora del sujeto. El yo, la interioridad, la entendamos como la entendamos, define tanto al ser humano como al conocimiento, pero el Romanticismo va más allá incluso, define también el mundo a través del obrar y del pensar del hombre.

Partiendo de aquí, resulta llamativa la postura de Isaiah Berlin que ve en esta forma de pensamiento, digamos intimista, casi un complejo de inferioridad. Para él, una de las características definitorias del Romanticismo es la reafirmación de la interioridad, típicamente alemana, que refleja, casi un ocultamiento del sujeto en sí mismo frente a un mundo políticamente hostil, que no le permite desarrollarse, y frente a la hiriente opulencia y superioridad intelectual francesas. Este «complejo de inferioridad» sería según él la causa del intimismo, tan característico del Pietismo alemán. Por tanto, la espiritualidad

5 Este fue un tema importante para los científicos y pensadores del momento. Fue, por ejemplo, casi el único punto de discordia entre A. v. Humboldt y Goethe, por lo demás grandes amigos y colaboradores. Para disgusto de Goethe, Humboldt, que como alumno de Werner en la Bergakademie salió de Alemania defendiendo el Neptunismo, volvió de su viaje a Latinoamérica convencido de lo contrario. Cfr. A. Wulf, La invención de la naturaleza. El nuevo mundo de Alexander von Humboldt. Barcelona: Taurus, 2016, pp. 248-49.

$6 C f r$. Système minéralogique et cosmologie chez Novalis ou les plis de la terre, pp. 68 y 146 . 
típicamente alemana, origen de ese peculiar subjetivismo que se desarrolla en el pensamiento romántico, es simplemente una reacción al poderío francés. No niego que la situación político-económica influya en la deriva intelectual de un país, pero tampoco podemos olvidar el profundo rechazo que el terror produjo en los intelectuales alemanes, que fue realmente detonante y acicate para corregir el rumbo y crear una forma diferente de pensamiento, una 'revolución alemana'. Sin olvidar el innegable carácter profundamente espiritual del pensamiento alemán de la época.

La espiritualidad que impregna el movimiento romántico alemán es el Luteranismo y, muy a menudo, como en el caso de Novalis, el pietismo. ${ }^{7}$ La interioridad agustiniana que en Lutero se convierte en condena a toda exterioridad ( $«$ la verdad es la interioridad $»^{8}$ ), se transforma, en el Romanticismo, en lugar y fuente de la unidad. En el caso de Novalis en «lugar de transformación», naturalmente bajo determinadas condiciones o, digámoslo así, habiendo alcanzado el propio sujeto un determinado estado, que a continuación intentaré dilucidar. El yo, bajo todas sus posibles interpretaciones, adquiere, por tanto, en el pensamiento romántico alemán, enormes dimensiones. Ya no es simplemente lo que acompaña a todas mis representaciones, como lo era para Kant, es el lugar donde todo sucede, en Novalis el lugar de la realización del infinito y divinización de lo real. En contra de lo que parece, esto no supone una negación de lo exterior, sino una indisoluble relación en un movimiento único cuyo polo activo es el sujeto.

En el caso de nuestro autor lo anterior resulta muy claro si analizamos su postura frente al cuerpo. Para él, como para la Ilustración francesa, todo comienza en el cuerpo. Conocemos a través de los sentidos, que constituyen la posibilidad de todo desarrollo, pero para nuestro autor ya no determinan sus límites, en todo caso la forma de su expansión. Novalis sabrá aunar ambas visiones, idealismo y empirismo, pues ninguna de ambas versiones descarta para él la opuesta, pero de forma muy diferente a Kant. Para él no es cuestión de alternancia o suma de capacidades, de yuxtaposición de la información, la que viene de los sentidos y las categorías del entendimiento. La subjetividad comienza en el cuerpo su ejercicio, éste - el cuerpo- juega un papel fundamental en el conocimiento de la verdadera realidad. En esa conjunción lo que se produce es una simultaneidad de capacidades que actúan a la par, y una pluralidad de información que interactúa complementándose, podríamos decir que se inter-penetran. El verdadero conocimiento, dice repetidamente

7 Su padre perteneció a la Herrnhut Brüderschaft de Zinzendorf, movimiento no del todo ortodoxo, y mantenía en su casa un ambiente estricto en este sentido.

$8 C f r$. T. Aizpún, Kierkegaards Begriff de Ausnahme. Der Geist als Liebe. München: Akademischer Verlag, 1983. 
en Los discípulos de Saís, comienza con la ejercitación de los sentidos. Pero el conocimiento no es reproducción o construcción de un fenómeno, sino su transformación. Tanto en el sujeto como en el objeto, el resultado es la alquimia producida desde la interioridad, de forma que lo conocido no es lo que estaba ahí antes de ser observado, y el observador, si de verdad conoce, tampoco es el que estaba ahí antes de conocer. El mundo es realmente una obra de arte.

Este conocer, que parte de y produce una intimidad, es necesariamente gozoso, también sensualmente gozoso. La unidad del hombre y el mundo en la que se da esa verdad es también una Gaia ciencia. Hay que volver a la alegre verdad de los antiguos (que Novalis llamaba «la Edad de Oro») y fusionarla con la verdad cristiana, ciertamente entendida a su modo.

\section{Cuerpo y espíritu: la dialÉctica de Novalis}

En Novalis, encontramos desde el principio, es decir ya desde sus primeros escritos y poesías juveniles, un mestizaje casi natural entre los hombres y los dioses. ${ }^{9}$ La Gaia ciencia, el canto a la vida y la capacidad pagana de corporeizar a sus divinidades coexisten con la unicidad y espiritualidad del Dios cristiano. Para él, la encarnación de Cristo rescató también a Orfeo de una muerte segura por perseguir el amor y la vida. El Cristianismo nos ofrece la vida eterna, pero la vida es vida, diría Novalis, no una quimera intelectual. Casi podríamos decir que Hardenberg da respuesta al problema Kierkegaardiano: la desesperación por no poder elegir al mismo tiempo a Dios y a Regina, compaginar el amor con el Amor. Ambos buscan el conocimiento eficaz, algo imposible desde el puro Luteranismo, desde la interpretación de Dios como lo Absolutamente Otro, o como lo Otro escrito con mayúsculas. Novalis recupera a Sophie sin renunciar a Dios, une a Cristo y Orfeo, o mejor rescata a Orfeo gracias a Cristo, la vida a través de la Vida, o lo que es lo mismo a través de la muerte. ${ }^{10} \mathrm{La}$ clave está en el cuerpo.

Cristo nos devuelve el amor y lo hace posible en la eternidad, porque acepta un cuerpo y, por tanto, también la muerte. Según Novalis, ese es el gran triunfo del Cristianismo: la superación de la muerte, algo no sólo posible desde la corporeidad, sino en la corporeidad, realizable en ella. En sus Cánticos Espirituales incluso habla de la pregunta por el cuerpo como la clave para entenderlo todo.

9 Cfr. L. Margantin, «Le corps des dieux. Les figures d'Orphée et de Jésus chez Novalis», Romantisme. Rév. du XIX. Siècle, 103 (29), 1999, pp. 5-17, p. 6.

10 Y ya el amante que la fe conforta / no llora de dolor ante una tumba, / Ya no podrán robarle / el precioso tesoro de su amor- / Para aplacar su anhelo/le brinda ardiente exaltación la noche, / y los hijos del cielo / velan fieles sobre él. Novalis, «Himnos a la noche», Himnos a la noche \& Cánticos espirituales (ed. Bilingüe). Valencia: Pretextos poesía, 2001, p. 63. 
¿Quién ha descifrado/el elevado sentido del cuerpo terrestre?

¿Quién puede decir/que comprende la sangre?

Un día todo será cuerpo/Un solo cuerpo/en la celeste sangre

Nadará la pareja feliz. ${ }^{11}$

Ya Schiller se había quejado de la desaparición de los dioses, que todavía pervivían en la Grecia clásica, gracias a que eran todavía humanos, así como los hombres eran divinos. También para Novalis la separación lleva a la muerte, y la causa está más allá de la Ilustración, está en el propio Cristianismo y es el olvido del cuerpo llevado a cabo por la Reforma. Con el rechazo a los santos, las reliquias, etc., Lutero quiso espiritualizar y, por tanto, purificar el Cristianismo, pero lo que realmente sucedió, es la total separación de Dios y los hombres, de hecho, la secularización del Cristianismo. Nos hemos quedado en la letra dirá — pues fundamentalmente en las escrituras se reconoce la manifestación de Dios - , pero sin cuerpo, lo divino deja de ser comprensible, el mundo pierde su sentido. La necesidad de sentido es necesidad de cuerpo. ${ }^{12}$

Si sólo en las escrituras reconocemos la presencia de lo divino, si el mundo deja de ser un jeroglífico que esconde Su presencia, la encarnación se convierte en una abstracción y al deshumanizar a Dios, también el hombre pierde su divinidad. Afirma que un hombre que deviene espíritu es a la vez un espíritu que deviene hombre; el espíritu se debe encarnar y el cuerpo espiritualizar, se debe producir una transformación, una transfiguración (Verklärung) de ambos. ${ }^{13}$ Esta es la forma especial de dialéctica que propugna Novalis para mantener y explicar la vida, la infinitización del mundo gracias a la fuerza de los opuestos o de las fuerzas opuestas. Todo esto es posible en la figura de Cristo, que adoptando un cuerpo y aceptando en consecuencia la muerte, la convierte en vida. La muerte es la «romantización» por excelencia. Dado que la muerte es la 'no-forma', es, diríamos con el lenguaje actual, la posibilidad de toda forma, y de superación de todos los límites. En eso consiste justamente la «romantización» que Novalis propugna: un proceso de ‘infinitización' de lo real, incluido el hombre, mediante la creación continua de nuevas formas.

Novalis lleva a cabo en este campo, crucial en su pensamiento, otra de las muchas síntesis, Versöhnungen, que van poco a poco acercándonos a la Totalidad y al Uno, pero también a la eternidad y la felicidad. Novalis se acerca al Catolicismo y sus prácticas, tenidas por los reformistas como supersticiones, justamente porque nos acercan al cuerpo, manifiestan una espiritualidad corporeizada. Es cierto que también Zinzendorf, a cuya secta, los Herrenhut,

11 Novalis, «Cánticos espirituales VII, Himno», Himnos a la noche \& Cánticos espirituales, p. 113.

$12 C$ fr. «Le corps des dieux. Les figures d'Orphée et de Jésus chez Novalis», p. 9.

13 Ib., p. 17. 
perteneció su padre, le da mucha importancia al cuerpo (Körper) que distingue de la carne (Fleisch). La carne sería como una impureza, un residuo del propio cuerpo. ${ }^{14}$ Para Novalis, en Cristo se unen finito e infinito, alma y cuerpo, en Él co-existen y se hacen reales. El sentido no es así algo previo al hombre, se crea, es acción poética realizada en el cuerpo. Por eso Cristo cambia el mundo, nos enseña a construir uno nuevo en donde la inmortalidad y la felicidad de la sensualidad son ambas, y al mismo tiempo, posibles. Vivir es a la vez una Bildung del hombre y del mundo. Cristo rescató a Orfeo, la antigüedad perdida, por eso es, simultáneamente, la muerte y la salud. ${ }^{15}$

\section{NovAlis, UN ROMÁNTICO ILUSTRADO}

En lo que se refiere al complejo de inferioridad de los alemanes frente a los franceses del que habla Berlin, ${ }^{16}$ si lo hay, Novalis es una excepción. Friederiech von Hardenberg, al contrario que Lessing, Kant, Herder o Fichte, de origen muy humilde, ${ }^{17}$ provenía de una antigua familia (su padre era el barón von Hardenberg) y recibió una esmerada educación. Tal vez por esta razón su profunda religiosidad no entra en absoluto en conflicto con el empeño sistemático y científico de su pensamiento. Su formación científica tampoco fue exclusivamente filosófica y teológica como en otros casos, sino con un fortísimo componente de lo que hoy llamaríamos «ciencias», fundamentalmente las matemáticas, la física, la química y la geología, que en cierto modo abarcaba a todas ellas. Esto proporciona realmente a su pensamiento, profundamente romántico nadie lo duda, un carácter muy especial, que no tiene nada que ver con el provincianismo que denunciaba Goethe en sus contemporáneos. Novalis, en la Academia de Minas de Freiberg, la Bergakademie, ${ }^{18}$ donde realmente se forma su pensamiento (1797-1799), se codea con estudiantes de todas las nacionalidades. La perspectiva de Novalis tiene un marcado carácter científico, piensa a partir de los descubrimientos más novedosos de la época, como el cálculo infinitesimal, que definirá uno de sus conceptos emblemáticos la «romantización».

14 Ib., p. 11.

15 Cfr. «Himnos a la noche», p. 55.

$16 C f r$. I. Berlin, Las raíces del romanticismo. Madrid: Taurus, 2000, p. 58ss.

17 Hegel, Schelling, Schiller y Hölderlin eran de clase media baja. Goethe era un burgués rico, aunque luego alcanzó un título. Sólo Kleist y Novalis han sido lo que, según aquellos tiempos, denominaríamos caballeros terratenientes. (I. Berlin, pp. 63-64).

18 Fundada en 1765, justo tras la guerra de los siete años, es una de las primeras escuelas técnicas del mundo y atrae estudiantes de todas partes. En ella trabajaban profesores de diferentes campos que podían ayudar a mejorar la explotación minera de Sajonia. Cfr., Système minéralogique et cosmologie chez Novalis ou les plis de la terre, p. 55ss. Actualmente se le conoce como Technische Universität Bergakademie Freiberg. 
Por otra parte, como el pensamiento ilustrado, el de Novalis, y el de todo el llamado «Idealismo alemán», tiene un marcado carácter sistemático, aspira a un conocimiento total y para ello crean sistemas de pensamiento. En el caso de nuestro autor su anhelo quedó truncado por su prematura muerte, con 31 años, pero las casi 600 páginas de notas de lo que conocemos como «Fragmentos» destinadas, parece ser, a la elaboración de una Enciclopedia siguiendo el modelo francés, dan prueba de ello y del polifacético carácter de su investigación. Sin embargo, entre ambos modelos de saber total hay una gran diferencia, si la Ilustración francesa fundamenta su sistema en la exclusión (a través de la delimitación axiomática y definitoria omnis determinatio ist negatio) y el análisis, la obsesión romántica es no dejar nada fuera, y Novalis no es una excepción. Eso no hace menos loable su afán enciclopédico, del que dan fe los Fragmente, y su continua búsqueda de la metodología adecuada para tal conocimiento.

Para Novalis, la operación del intelecto (y del alma) que nos permite alcanzar de manera procesual — como tendencia ilimitada hacia el todo- la unión es la «romantización», la progresiva superación de todo límite. Es un ir más allá de uno mismo para alcanzar la verdad que es el todo, pero no en sentido hegeliano como pura adición, movida por fuerzas exteriores, casi mecánicas. La acumulación romántica es cualitativa, es absolutización y universalización, ${ }^{19}$ pero también transformación. El todo es la suma de las formas creadas por el espíritu del hombre, algo que no es posible sino en unión con la naturaleza. Por eso, comprender el alma del hombre es imposible sin comprender el alma del mundo o la naturaleza, incluidos los conceptos de «noche» y de «caos», que en Novalis son prácticamente equivalentes. La naturaleza no tiene una forma dada e inmutable, es diferente antes y después de entrar en diálogo con el quehacer artístico del ser humano. La naturaleza, en estado puro, es una fuerza desbocada y aterradora, demás invencible. Pero ese no es su único estado posible.

Como dice Isahia Berlin, refiriéndose a los ilustrados, cuando hablaban de «naturaleza» se referían a la vida, y por «vida» no entendían lo que uno veía, sino aquello hacia lo que la vida misma aspiraba. ${ }^{20} \mathrm{El}$ concepto de «naturaleza» en Novalis no se distancia realmente de esta definición, pero da un salto que lo hace cualitativamente diferente. Como para el pensamiento ilustrado, también para Novalis, la naturaleza es el campo de acción del hombre, pero más que domeñada aquí habría que decir «domesticada», debe ser ordenada dentro de una relación. La naturaleza, que es un infinito flujo de fuerzas anterior a la forma, debe adquirir un orden, debe ser formalizada para convertirse en una naturaleza «más noble». El científico crea modelos y los aplica. Si no lo hace con violencia, la propia naturaleza se transforma, aprende maneras «más

19 Fragmente, p. 483.

20 Cfr. I. Berlin, p. 49. 
delicadas» que hacen posible establecer un diálogo con ella, podríamos decir que con el trato se humaniza. Como en la Edad de Oro, la ciencia actual debe aprender su lenguaje para hacerse su amiga.

Poco a poco comenzó su corazón [de la naturaleza] a emocionarse de nuevo con lo humano, sus fantasías devinieron más serenas, de nuevo era tratable, y respondía gustosamente a quien le preguntaba amablemente; y así, progresivamente, parece retornar la antigua Edad de Oro, cuando era amiga, consoladora, sacerdotisa de los hombres. Cuando obraba milagros y vivía entre ellos, estableciendo un trato celestial que los convertía en inmortales. ${ }^{21}$

\section{LA NATURALEZA: EL PRINCIPIO DE TODO}

La naturaleza, que a veces podemos identificar con el alma, o incluso la noche, es, para nuestro autor, a la vez objetiva y subjetiva. El concepto de «naturaleza» nos habla de un sustrato común al hombre y al mundo que no sólo establece entre ellos una armonía, sino una continua comunicación a través de su fluir. Realmente existe una semejanza entre ambos que hace que, para entender real y correctamente la esencia del mundo, de la naturaleza, haya que considerarla antropomórficamente. Los que ya no entienden el juego de la imaginación no pueden verlo, pero la consideración antropomórfica de la historia del mundo y del hombre y, en consecuencia, también de la naturaleza, tal y como hacía, por ejemplo, la mitología, no sólo es concebible, sino que es la forma correcta de conocimiento. ${ }^{22}$ La relación que debemos establecer con la naturaleza es una relación entre semejantes, pues constituye la única totalidad con la que el ser humano se puede comparar, solo ella es su igual y, por tanto, sólo con ella podemos establecer una relación equilibrada. Todo lo que tiene historia, y la naturaleza la tiene, tiene origen divino y es espiritual. La naturaleza cumple, por tanto, las condiciones para una relación de tú a tú.

La Naturaleza no sería Naturaleza si no tuviese espíritu. No sería el único reflejo (imagen) de la humanidad, ni la inevitable respuesta a esta misteriosa pregunta, o la pregunta a esta respuesta infinita. ${ }^{23}$

$\mathrm{Si}$, por el contrario, nos empecinamos en controlarla y destruirla (como a menudo hace la ciencia), ésta se nos presentará bajo su cara más temible, como «un terrible molino de muerte» (eine furchtbare Mühle des Todes) con

21 Novalis, Poesías Completas \& Los discípulos en Saís. Barcelona: DVD poesía, 2000, p. 254. Traducción propia.

22 Cfr.ib., p. 248.

$23 I b$. p. 284, Traducción propia. 
una fuerza destructiva tal, que sólo la muerte podría salvarnos. ${ }^{24}$ Pero si comprendemos, como en la «infancia de los pueblos», que el rostro de la naturaleza es el rostro de la divinidad, ${ }^{25}$ si aceptamos que gracias a ella compartimos el mismo espacio que la divinidad ${ }^{26}$ y alcanzamos nuestra propia eternidad (la historia será el sueño de un presente infinito ${ }^{27}$ ), entonces debemos seguir un método diferente de conocimiento, que es casi un diálogo, una colaboración. Un método que ciertamente comienza por los sentidos, pues sin el cuerpo no podemos llegar al espíritu, pero este nuevo método pasa por la intuición y la ciencia simultáneamente, exige la colaboración —actuación simultánea- y el desarrollo progresivo de todos los sentidos. Este método de conocimiento no debe ser, por tanto, exclusivo, sino inclusivo, abarcar lo más posible, tanto a nivel del objeto como del sujeto.

Novalis afirma en Los discípulos de Saís:

Denominamos naturaleza a la esencia de aquello que nos conmueve, y por tanto la naturaleza está en relación directa con las partes de nuestro cuerpo que llamamos sentidos [...] Así es la naturaleza esa asombrosa comunidad, en la que nos introduce nuestro cuerpo, y que nosotros conocemos proporcionalmente a nuestras estructuras organizativas y capacidades. ${ }^{28}$

Primero hay que investigar el cuerpo, dirá y para eso es necesario pensar de formas diferentes (mannifach im Denken müssten geübt haben ${ }^{29}$ ). Esta pluralidad del pensamiento nos ayuda a observar atentamente todas nuestras sensaciones ${ }^{30}$ porque el hombre debe ponerse totalmente en todo lo que hace, su actuar debe ir acompañado de atención plena, indivisa, dirá (ungetteilte Aufmerksamkeit ${ }^{3 l}$ ). De esa forma de atención surgen espontáneamente nuevos pensamientos, nuevas sensaciones, nuevas formas; se convierte en intuición intelectual. Si el hombre comprendiese la interna unidad de todo lo que existe, si no se empeñase machaconamente en dividir y dividir todo, buscando ser como Dios, llegaría a ser maestro del eterno juego de la naturaleza y sería feliz. ${ }^{32}$ Realmente el pensar, dirá, es sólo un «sueño del sentir», consecuencia de una vida debilitada. ${ }^{33}$

$24 I b$. p. 260

$25 \quad I b$. p. 253.

26 Cfr.ib.p. 257.

$27 \quad I b$. p. 257.

$28 I b .$, p. 280.

$29 I b .$, p. 280.

30 Cfr.ib., p. 282.

$31 \quad I b .$, p. 278.

32 Cfr.ib., p. 276.

33 Das Denken ist nur ein Traum des Fühlens, ein erstorbenes Fühlen, ein blassgraues, 
Los sentidos, por tanto, nos abren el camino a la unión real con lo originario, con ese fluir común al mundo y al hombre, que constituye lo verdaderamente real, das Urflüssige. Cuando el ser humano se hunde en la contemplación del sentir, alcanza la fuente de la creación, die Erzeugungsgeschichte der Natur, ${ }^{34}$ y cada objeto, todo lo que puede parecer inamovible se une al infinito fluir de la vida (la Naturaleza escrita con mayúscula), el hombre mismo se convierte en creador. Novalis lo explica diciendo que surgen «composiciones de la Naturaleza», lo que antes había denominado «modelos», ${ }^{35}$ esos modelos que fabrica el hombre para domesticar la naturaleza que lo aterra. En este nivel de la reconciliación, de unión, se manifiesta «el genio del amor», la fuerza originaria, y se produce una nueva relación entre el Yo y el Tú. ${ }^{36}$ Este es el último paso que nos conduce a la eternidad. Cuando permitimos que la naturaleza se desarrolle plenamente en nuestro interior, cuando dejamos que surja totalmente, entonces no estamos a nivel del pensamiento, sino del ánimo (Gemüht) y surge un poderosos sentimiento que es el Amor (Liebe), la felicidad (Wollust) ${ }^{37}$ Unido a esta corriente el hombre es, por primera vez, un sí mismo y se puede unir realmente a otros seres humanos, otros sí mismos, entonces encuentra su verdadero ser o naturaleza.

El hombre, como ser pensante, regresa a la función originaria de su ser, a la contemplación creadora. Regresa a ese punto en el que originar y saber se encuentran en una maravillosa relación de intercambio. Regresa a ese momento creador del verdadero gozo, de la auto-realización interior. ${ }^{38}$

\section{EL PENSAMIENTO Y LA INTUICIÓN: CÓMO CONOCER LA NATURALEZA}

No podemos olvidar el papel que la intuición juega en todo este proceso. La intuición, que los poetas o «los hombres-niños» (kindlichen Menschen ${ }^{39}$ ) poseen, es como llama Novalis a ese reconocimiento de las formas que surgen de la contemplación. En la contemplación el hombre no está desligado del mundo, no se convierte a sí mismo en isla Como ya he dicho, para que se produzca un conocimiento real de la naturaleza, el individuo ha tenido que permitirle un desarrollo pleno en sí mismo, el ser humano tiene que alcanzar

schwaches Leben. Ib., p. 276.

$34 I b .$, p. 290.

35 Cfr.ib., p. 255.

36 Cfr.ib., p. 290.

37 Cfr.ib., p. 294.

38 Cfr.ib., pp. 288 y 290. Des innern Selbstempfängnisses. Traducción propia

$39 \mathrm{Ib} ., \mathrm{p} .256$. 
previamente una cierta plenitud (aufgeblühte Menschen ${ }^{40}$ ): haber desarrollado una poética vida interior, por tanto, una incansable capacidad de contemplar, libre y artísticamente, los más pequeños rasgos de la naturaleza, a través de los sentidos bien entrenados, y no sólo de este o aquél, sino de todos. Al menos todos ellos tienen que estar despiertos.

Tampoco podemos olvidar - porque forma parte así mismo de las condiciones para desarrollar esa especie de «órgano interior», que hace posible la intuición-, la necesidad de tener una actitud recta. Aquí, la educación pietista de Hardenberg se manifiesta plenamente: quién no posee un ánimo temeroso de Dios (gottesfürchtiges Gemüth) ${ }^{41}$ no puede establecer contacto profundo con su obra, no puede «hablar» con la naturaleza, porque la naturaleza tiene espíritu y, por tanto, sólo desde el espíritu puedes relacionarte con ella. El actuar moral, es el más grande y el único intento posible, para desentrañar todos los misterios de la enorme variedad de manifestaciones, ${ }^{42}$ afirma. Esta postura puede parecernos «poco científica», como el intento del pensamiento alemán en general, que hemos comentado anteriormente, de explicar científicamente el mundo a partir de las imágenes bíblicas, pero esta forma de actuar es más bien un cientificismo del pensamiento religioso, que una versión irracional de la ciencia. En el caso de Novalis su afirmación de la necesidad de una rectitud moral para entender la naturaleza es totalmente coherente. Si el único camino para el verdadero conocimiento es el «hermanamiento» con la naturaleza - descubrir todo lo que nos une y perfeccionarlo, para hacer posible el diálogo - y si eso sólo es posible para un hombre desde la unidad consigo mismo y un cierto perfeccionamiento de todas sus capacidades, si de alguna manera el diálogo o la unión sólo puede darse entre dos realidades que han alcanzado un cierto nivel de desarrollo, ¿cómo no va a ser necesario también un desarrollo moral en el sujeto?, la moralidad en este contexto es coherencia interior y adecuación a la totalidad, es realmente un nombre de la unión, una de sus formas, un acompasamiento interior y exterior. De esa comunión surge la intuición creativa.

Podría tal vez parecernos, por lo expuesto hasta aquí, que de algún modo Novalis defiende una forma pasiva de conocimiento, algo parecido a una iluminación, pero no es así. Ya hemos dicho que cuando nuestro autor habla de verdadero conocimiento habla de contemplación creadora. Hemos dicho también que la naturaleza en estado salvaje no es cognoscible, el hombre tiene que establecer no sólo una relación con ella, sino las condiciones de posibilidad

$40 \quad I b ., p .256$.

41 Ib., p. 256.

42 Sittliches Handeln ist jener grosse und einzige Versuch, in welchem alle Rätsel der mannichfaltigsten Erscheinungen sich lösen. Ib., p. 264. Traducción propia. 
de dicha relación. Para ello tiene que crear modelos, sistemas, y al crearlos, la forma del objeto y la del sujeto se transforman y, progresivamente, se asemejan. El hombre tiene que alcanzar un cierto orden que exige un desarrollo (Bildung), este orden se aplica también a la naturaleza que se desarrolla suavizando su fuerza, haciéndose asequible, ordenándose (Bildung). Ambos se acoplan a través de una ordenación activa, de una orientación y formalización de sus respectivas fuerzas.

Con este fin, la teoría de la naturaleza conlleva la elaboración de una minuciosa descripción de su historia, reuniendo todos los detalles que sean posibles. La meta es la reunificación del todo, pero para alcanzarla no queda más remedio que reunir el mayor número posible de observaciones y sistematizarlas. Novalis no deja de ser un científico y un científico de su tiempo, no rechaza, ni niega la utilidad de lo cuantitativo. Todo conocimiento comienza con la observación (aunque esta tenga metas y maneras diferentes a las defendidas por la Ilustración francesa), y el segundo paso es la ordenación de esos conocimientos. Este es el único camino para «domesticar» la naturaleza, para que deje de ser simplemente un caos.

Algunos piensan, en la actualidad, que no merece la pena seguir ordenando las subdivisiones sin fin de la Naturaleza, y que además es una empresa peligrosa, infecunda y sin salida. Del mismo modo que nunca se descubrirá el elemento más pequeño de un cuerpo sólido, ni la fibra más simple, ya que todas las grandezas se van desintegrando por arriba y por abajo en el infinito. Así sucederá con los géneros y clases de cuerpos y fuerzas; se llegará, aquí también, a nuevas especies, a nuevas síntesis, a nuevas apariencias, así hasta el infinito. [...] Es cierto que se pierde un tiempo precioso en contemplaciones ociosas y en aburridas enumeraciones; al final todo acaba en una verdadera demencia, un verdadero vértigo ante el espantoso abismo. Además, por muy lejos que se llegue, la Naturaleza será siempre un terrible molino de muerte. ${ }^{43}$

Pero los que así piensan se equivocan, ¿acaso no distinguen en la Naturaleza la fiel reproducción de sí mismos?, ${ }^{44}$ todo el trabajo realizado para conocerla redunda en autoconocimiento. Lo que busca el teórico de la naturaleza es la sistematización de su mundo intelectual, de sus pensamientos y armonizar este orden con el universo. Cuando así lo hacemos surge, de forma espontánea, su imagen real, fiable, la fórmula del universo. ${ }^{45} \mathrm{El}$ conocimiento no es, por tanto, algo pasivo, sino continua actividad, a imitación del artista. Este continuo

$43 \quad I b .$, p. 259.

$44 I b .$, p. 262. Traducción propia.

45 Cfr.ib., p. 290. 
estructurar es también formador, no un mero remover las cosas, si se hace correctamente es verdadera actividad.

El quehacer de quien aspira a ser «maestro de la naturaleza» pone la actividad por encima de todo, su esencia es el hacer y el crear con sabiduría $y$ voluntad. ${ }^{46}$ Sólo desde esta perspectiva podemos entender la afirmación de Novalis de que el sentido del universo es la Razón ${ }^{47}$ puesto que el trabajo interior y exterior en el hombre se encuentran. Porque este desarrollo de sí mismo (comenzando por el ejercicio y desarrollo de todos los sentidos, pero sin olvidar el conocimiento científico), que me lleva también a la contemplación y ordenación de la naturaleza, tiene como meta el infinito diálogo de los dos infinitos, el mundo y el hombre, la creación, en el mundo, de un orden superior, moral, y la creación de una identidad fuerte, inexpugnable, y clara.

Quién así actúa es el «hombre despierto» (wachende Mensche), ${ }^{48}$ es el verdadero y el único señor del mundo, porque, en cierto modo, el hombre es el creador del mundo, ya que adquiere la forma que él le da. La naturaleza es su propio reflejo, (Abdruck ihrer selbst) ${ }^{49}$ huella de su hacer, impronta de su pensar y su sentir. Somos la fuente, dice uno de los discípulos de Saís, de ese mundo más limpio al que aspiramos. Si comprendemos esto, el teatro del mundo nos resultará totalmente familiar, nada nos sorprenderá, porque el mundo es un libro y nosotros tenemos la clave para descifrarlo. ${ }^{50}$ Realmente es el libro del espíritu.

En este sentido podemos afirmar también que el pensamiento es un «sueño del sentir», como un sentir desvitalizado, moribundo, ${ }^{51}$ ya que el verdadero conocimiento es acción desde el sentimiento, es amor o al menos una forma de éste, es ordenación y reunificación, por eso produce alegría y conlleva placer. El puro pensar es lo que le queda al hombre que ha perdido el contacto consigo mismo, con su realidad más profunda y, en consecuencia, con el mundo. Y si te has desconectado de ese fluido originario, sólo estás vivo a medias. En cierto modo el conocimiento es amor, pero este no es simplemente un don, en esto Novalis se acerca de nuevo al catolicismo, es actividad, y en ese sentido conquista.

$46 I b .$, p. 292. Traducción propia.

47 Cfr.ib., p. 264.

48 Cfr.ib., p. 264.

49 Ib., p. 262.

50 Cfr.ib., p. 262.

51 Cfr.ib., p. 276. 


\section{EL VERDADERO CONOCIMIENTO: LA IMAGINACIÓN Y LA MAGIA}

La ciencia, como ya decía Aristóteles, busca lo universal, las leyes generales que mueven el mundo. Pero el Romanticismo ha pasado a la historia, entre otras cosas, por «descubrir» la importancia de lo individual, lo diferente. Novalis tampoco en este aspecto es una excepción, más bien la culminación de este axioma, sin embargo, para él no existen sustancias simples, lo simple no es representable y, por tanto, es una fantasía. ${ }^{52}$ Son las relaciones y el movimiento infinito, lo que caracteriza lo real, este movimiento consiste en el continuo surgir de variaciones y polaridades que lo hacen posible. La realidad está en continuo cambio, es acción poética, surgir de la diferencia. Digamos que sin individualidad no es posible la vida del Todo.

Hay, por tanto, dos fuerzas que explican el continuo movimiento, el fluir de lo real: una analítica y disociativa (vermannichfaltende Kraft), necesaria para el desarrollo del mundo, para el surgir de esa infinita variedad de formas, y la otra ordenadora, sistematizadora y reunificadora (einende, systematisierende Kraft), necesaria para no perderse en el caos, en la absoluta dispersión. Esta segunda fuerza es la Bildung, que da forma, ordena sin matar, sin anular el impulso necesario a la infinitud, que se realiza por la ilimitada y continua creación de formas. Vista así la acción, la imaginación se entiende como conocimiento práctico (praktische Vernunft ${ }^{53}$ ), como un actuar que produce conocimiento o un conocimiento que sólo puede darse como resultado de la acción. Por eso la sistematización romántica (romantisieren) no fija, es un orden vivificante, una creación. Estas fuerzas, tanto físicas como espirituales, reflejan la idea que nuestro autor tiene del caos.

Su idea de «caos», concebida a partir de sus estudios geológicos, representa la potencialidad infinita, ilimitada más bien, de la continua variación de relaciones. Por eso para él «caos» significa tanto origen, fuerza sin forma, como orden poético o romántico, como lo denomina en algunos casos, significando orden no fijo, sino en continuo cambio, estructura permanentemente abierta. La variedad de fuerzas produce una continua variedad de formas, y esto es aplicable tanto al hombre como al mundo. Cada cuerpo es un caos de numerosas figuras-fuerzas, dirá. ${ }^{54} \mathrm{El} \mathrm{libro} \mathrm{del} \mathrm{mundo} \mathrm{no} \mathrm{está} \mathrm{terminado} \mathrm{y,} \mathrm{por} \mathrm{tanto,}$ en su dinamismo conviven realmente caos y orden. El sistema concebido por Novalis es un arte de las variaciones, elaborado intelectualmente a partir del cálculo infinitesimal recién descubierto, un perpetuum mobile, una danza. El conocimiento y la contemplación no pueden entenderse como en la filosofía

52 Système minéralogique et cosmologie chez Novalis ou les plis de la terre, p. 108.

53 Fragmente, p. 86.

54 Système minéralogique et cosmologie chez Novalis ou les plis de la terre, p. 101, nota 17. 
clásica, como contemplación de lo inmutable, sino como un acompasarse, en tu propia danza y ritmo interior, al movimiento del mundo. Una activa Bildung que va, simultáneamente, hacia dentro y hacia fuera. La Bildung der Erde, de la tierra, es inseparable de la Bildung des Menschen, del hombre. ${ }^{55} \mathrm{El}$ ser humano debe realizar también su camino hacia dentro y hacia fuera, está sometido igualmente a las fuerzas disgregadoras y las fuerzas ordenadoras y no debe renunciar a ninguna de ellas. La necesaria determinación del yo exige, para su realización, relacionar este yo con algo, y esto se lleva a cabo a través de las diferencias, dirá Hardenberg.

En este continuo movimiento de la vida y la muerte, la vida se mueve en un ámbito superior, entre el ser y el no ser, un campo inexpresable ${ }^{56}$ que hace posible el infinito potencial, lo infinito como progresión ilimitada. Como dice Safranski hablando de Schlegel, cuyo pensamiento influyó poderosamente en nuestro autor, «lo infinito es lo «supercomplejo». ${ }^{57}$

Desde esta visión de lo real es fácil comprender la importancia de la imaginación creadora (die produktive Einbildungskraft). El hombre, como el mundo, es una fuerza o mejor una suma de fuerzas en continuo movimiento, es caos y orden a la vez. La imaginación es nuestra capacidad formadora y, por tanto, nuestra posibilidad de Bildung, origen de nuestras fuerzas y capacidades, y en ese sentido nuestro mayor bien. ${ }^{58}$ La imaginación hace posible la «romantización», la potenciación cualitativa de todo lo real, incluidos nosotros mismos. Ciertamente, en cuanto fuerza, exige de nosotros un control para que no escape a nuestra voluntad, pues, aunque no depende de ninguna fuerza o atracción exterior, sino sólo de nuestra voluntad, la fuerza disgregadora en nosotros puede volverse dominante y entonces deja de ser la imaginación unidad de la intuición, origen y posibilidad de la magia, compañera que todo lo transforma $y$ lo hermana ${ }^{59}$ para convertirse en simple fantasía que nos conduce al mundo de los fantasmas. ${ }^{60}$ Por el contrario, si la imaginación actúa junto con la razón, entonces el resultado es la religión, conocimiento de la unión. La imaginación bien entendida no es otra cosa que razón práctica, ${ }^{61}$ es conocimiento que actúa. Entonces surge la magia.

La magia es la fuerza del «poetizar», del «romantizar». Proviene de la unión del mundo y el hombre en el interior de éste. Desde la unión, desde el

55 Cfr. Système minéralogique et cosmologie chez Novalis ou les plis de la terre, p. 183.

$56 C f r$. Fragmente, p. 186. Cfr. H-P. Dürr, Warum es ums Ganze geht. Neues Denken für eine Welt im Umbruch. München: Oekom, 2009.

57 Cfr. R. Safranski, p. 59.

58 Das grösseste Gut besteht in der Einbildungskrat. Fragmente, p. 303.

$59 C f r$. «Himnos a la noche», p., 51.

60 Cfr. Fragmente, p. 85.

$61 C f r$. Fragmente, p. 86. 
amor todo es posible porque el hombre se conecta con el ilimitado fluir aceptando todos los contrarios. La muerte es el Principio romantizante de nuestra $v i d a,{ }^{62}$ a través de la muerte conquista el hombre una existencia más liviana, más libre, es un paso más en la reconciliación de lo real, en la unión del yo con el Yo, de lo particular con el Todo, y ese es el lugar de la creación.

El acuerdo profundo entre ciencia y religión alcanza en Novalis su máximo desarrollo. Para él la angustia kierkegaardiana del ser humano que ansía desesperadamente a un Dios inalcanzable no tendría sentido. Desde su visión unitaria de la realidad todo hombre que vive de Dios y a través de Él, deviene necesariamente Dios. ${ }^{63}$ Cuando el ser humano realiza la unión, es uno y Todo, yo y Yo, es caos y orden al mismo tiempo, es como Dios, que siendo individualidad es el lugar de la síntesis, ${ }^{64}$ como el oxígeno dirá. En el proceso de «romantización», de superación continua de sus límites, el hombre se diviniza. La materia tiene que espiritualizarse y lo espiritual materializarse en este continuo vaivén. Este proceso se realiza gracias a la incesante creación de formas que la imaginación hace posible en el hombre. Y todo se produce en el espíritu y en la materia simultáneamente, por eso es eficaz, mágico. Novalis llega a afirmar que el hombre llegará a curarse a sí mismo, a ser su propio médico.

El conocimiento es, por tanto, medio contemplación, medio creación. Se mueve en el espacio entre el ser y el no ser. Novalis resulta muy avanzado a su tiempo cuando afirma que el mundo debe llegar a ser una obra de arte, lo que significa que cobra vida gracias a nuestra mirada (bringt durch das Auge hervor $\left.^{65}\right)$. Para nuestro autor, al igual que la Antigüedad que creó Winckelmann, la Naturaleza y su comprensión surgen simultáneamente. El verdadero científico, el poeta, se mueve en el campo de la vida, por tanto, en el de la transformación continua de lo real. El verdadero conocimiento no es sólo intelectual, es Bildung interior y exterior.

Cuando realiza este proceso, el ser humano se convierte en un perfecto y absoluto instrumento (Werkzeug) para sí mismo, ${ }^{66}$ consigue acompasar su ritmo con el ritmo del universo y bailar con él un mismo baile (beide sich schwingungenzugesellen), ${ }^{67}$ porque el alma tiene una naturaleza musical. En ese baile el conocimiento se convierte en creador y, en cierto modo en adivinación, otra idea de Schlegel. ${ }^{68}$ El cuerpo está muy lejos ahora de ser la cárcel del alma.

62 Fragmente, p. 190.

63 Jeder Mensch der von Gott und durch Gott lebt, soll selbst Gott werden, Fragmente, p. 188.

64 Fragmente, p. 179.

65 Cfr. Système minéralogique et cosmologie chez Novalis ou les plis de la terre, p. 50.

66 Cfr. Fragmente, p. 189.

67 Fragmente, pp. 516-17.

68 Cfr. R. Safranski, p. 47. 


\section{A MODO DE CONCLUSIÓN}

La búsqueda de un pensamiento eficaz, que culmine el proceso de perfeccionamiento del ser humano no es algo extraño al pensamiento occidental, en cierto modo [mi pensamiento] estaba más cerca de la 'magia' que de la mística, dice Elíade. ${ }^{69} \mathrm{El}$ también busca alcanzar lo trascendente sin perder lo sensible: un ser, un gesto se hacen sagrados; es decir, llegan a trascender este mundo, sin dejar de ser lo que siempre han sido: un objeto, un ser, un gesto. ${ }^{70}$ El problema de Kierkegaard cuando afirma que creer a pesar de la razón es un martirio, dirá, es que ha perdido la fe, ha olvidado el sentimiento de plenitud y casi orgiástico de que nuestra fe es creadora, de que el mundo se hace tal como creemos. ${ }^{71}$

El pensamiento de Novalis tiene algo de visionario; ya en el siglo XVIII fue capaz de intuir no sólo un modelo de mundo que en su época era una locura, sino sus bases científicas. Algunas de sus ideas: realmente todo está unido ${ }^{72}$ (el hombre y el mundo, la naturaleza, no existen separadamente) y además en continuo movimiento ${ }^{73}$; existen fuerzas de contracción y expansión que hacen posible el equilibrio de lo real y finalmente la vida misma - entendida ésta como un 'balanceo' entre el ser y el no ser y un acompasamiento de ritmos entre el hombre y el mundo ${ }^{74}$ - . La primera consecuencia de este movimiento vital es que la abstracción - en cuanto pensamiento puramente reflexivo, vuelto sobre sí mismo- debilita, ya que pensar, sentir e intuir son uno ${ }^{75}$. El mundo está vivo y tiene espíritu y Sólo el espíritu ve, oye y siente. ${ }^{76}$ Por eso antropomorfizar el mundo, verlo desde la vida, es la forma correcta de mirarlo, algo que hoy no produce ningún escándalo.

\section{REFERENCIAS BIBLIOGRÁFICAS}

Aizpún, T., Kierkegaards Begriff de Ausnahme. Der Geist als Liebe. München: Akademischer Verlag, 1983.

Berlin, I., Las raices del romanticismo. Madrid: Taurus, 2000.

Bohm, D. La totalidad y el orden implicado. Barcelona: Kairós, 1998.

69 M. Elíade, Las promesas del equinocio, p. 300.

$70 \mathrm{Ib}$

71 M. Elíade, Diario portugués, p. 1945.

$72 C f r$. D. Bohm, La totalidad y el orden implicado, p. 27.

$73 C f r$. D. Bohm, La totalidad y el orden implicado, p. 31 y 56.

$74 C f r$. H-P. Dürr, Warum es ums Ganze geht. Neues Denken für eine Welt im Umbruch, p. 106.

75 Fragmente, p. 85.

76 Fragmente, p. 103. 
Capra, F. La trama de la vida. Una nueva perspectiva de los sistemas vivos. Barcelona: Anagrama, 2003.

Dürr, H-P. Warum es ums Ganze geht. Neues Denken für eine Welt im Umbruch. München: Oekom, 2009.

Elíade, M. Diario portugués. Barcelona: Kairós, 2000.

Las promesas del equinocio. Barcelona: Taurus, 2018.

Hölderlin, F. Poemas de la locura (ed. Bilingüe). Madrid: Hiperión, 2006.

Inerarity, D. Hegel y el romanticismo. Madrid: Técnos, 1993

Kaku, M. El futuro de nuestra mente. Barcelona: Debolsillo, 2015.

Margantin, L. Système minéralogique et cosmologie chez Novalis ou les plis de la terre. Paris: Ouverture philosophique L'Harmattan, 1998.

«Le corps des dieux. Les figures d'Orphée et de Jésus chez Novalis», Romantisme. Rév. du XIX. Siècle, 103 (29), 1999, pp. 5-17.

Novalis, Gérmenes o Fragmentos. Sevilla: Renacimiento, 2006.

Fragmente (Originalausgabe). Hamburg: Tredition Classics.

Poesías Completas \& Los discípulos en Sais (ed. Bilingüe). Barcelona: DVD poesía, 2000.

Himnos a la noche \& Cánticos espirituales (ed. Bilingüe). Valencia: Pretextos poesía, 2001.

Pauli, W. Escritos sobre física y filosofía. Madrid: Debate, 1996.

Safranski, Rüdiger, Romanticismo. Barcelona: Tusquets, 2009.

Schneider, E. ySagan, D. La termodinámica de la vida. Barcelona: Tusquets, 2009.

Teodorani, M. Sincronicidad. El vínculo entre la Física y la Psique. Desde Pauli y Jung hasta Chopra. Málaga: Sirio, 2011.

Wulf, A. La invención de la naturaleza. El nuevo mundo de Alexander von Humboldt. Barcelona: Taurus, 2016

Teresa Aizpún Bobadilla es profesora de filosofía en la Universidad Rey Juan Carlos (Madrid). Doctora en Filosofía por la Ludwig-Maximilians-Universität de Munich (Alemania, 1993).

Lineas de investigación:

Su recorrido investigador comienza con la Antropología filosófica movida por el interés sobre la voluntad que le lleva a la estética como resultado de su tesis doctoral y se centra en la actividad creadora. Poco a poco la creación le lleva al campo de la ética como creación de sí mismo y actualmente esa capacidad creadora le ha llevado a estudios sobre la conciencia y sus diferentes aspectos. 
Publicaciones recientes:

«La visión moderna del conocimiento y su repercusión en el arte: la transparencia», en: Revista Internacional de Cultura Visual vol. 5 (2), 2018, pp. 73-80.

«El amor cortés: la Weltanschaaung de la literatura medieval», en: CAURIENSIA, Vol. XIII (2018), pp. 303-324.

Email: teresa.aizpun@urjc.es 